\title{
Problems of underwater cultural heritage research in the context of the Baltic Sea drainage basin ecology
}

\author{
Babek Asadov ${ }^{1}$, Alexander Baranov², Sofiia Baranova ${ }^{2}$, Anastasiia Bobrova $^{2}$, and Inga \\ Philippova $^{3, *}$ \\ ${ }^{1}$ Saint-Petersburg University of State Fire Service of EMERCOM of Russia \\ ${ }^{2}$ Herzen State Pedagogical University of Russia, St. Petersburg, Russian Federation \\ ${ }^{3}$ St. Petersburg University of Management Technologies and Economics, Russian Federation
}

\begin{abstract}
The article considers key issues of the underwater cultural heritage and the ways to reveal investigate and preserve it. Due to the lack of knowledge of the problem, the authors have developed a method that allows detecting the potential of the object in order to obtain the status of underwater cultural heritage in the future. These eventual objects are based on the UNESCO World Heritage List. The Baltic Drainage Sea is on the top of this List by the total number of these sites. The authors paid great attention to mark the wreck influence on ecological condition of the sea and they noticed the need of environmental monitoring. As a solution of some issues of preserving underwater cultural heritage. The term "ecology of underwater heritage" was proposed, as well as examples of international cooperation on the integration of environmental and archaeological underwater research.
\end{abstract}

\section{Introduction}

In the last decade, interdisciplinary research related to the Underwater Cultural Heritage $(\mathrm{UCH})$ has been gaining more and more popularity, because when studying it, it becomes obvious that, in addition to attractive perspectives, there are actual problems. The UCH first of all touched upon the issues of its own definitions, withdrawn by the 2001 Convention on the Protection of the Underwater Cultural Heritage and Operational Guide to the Convention, published in 2013 and expanding the understanding through the proposed characteristics of underwater objects and recommendations for work [1-3]. However, the definition of the convention turned out to be not exhaustive for many countries, therefore, research in this field by some state continues [4,5].

Much more attention is paid to identifying objects of underwater heritage and fixing their location at a point of water area. This activity is carried out by almost all states, but often without cooperation, which presents difficulties in maintaining a general register of UCH. At the moment, UNESCO has also not determined the nature of its own activities in this matter, only has compiled a list of 55 most striking examples of underwater heritage, including 7

\footnotetext{
* Corresponding author: geobobrova@,gmail.com
} 
World Heritage Sites. But the published list cannot be used as a register of underwater heritage, because the listed objects at the regulatory level are not designated as an UCH.

The least developed field of research of the underwater heritage of the Baltic region, as well as throughout the world, is the ecological aspect. In view of the fact that the type of "wreck and catastrophes" among all types of UCH is the most common - shipwrecks, according to an expert, are scattered about 3 million throughout the Oceans [6] - then attention should be focused on the relationship between wrecks and marine biota, requiring careful and prompt study [7]. In view of the fact that sunken ships rest on the bottom of the Baltic Sea for a long period, they take on a radically different role - in assimilation with the seascape, they represent an aquatic-anthropogenic complex that creates new ecological patterns [7-9].

The relevance of the work is determined by the object of study, designated as Underwater Cultural Heritage, the value of which is growing disproportionately today.

The aim of research was to identify the water area with the highest concentration of UCH objects as the most environmentally vulnerable.

To achieve this goal, it proposed to solve the following tasks:

- creation of the basis of the eventual underwater cultural heritage and gradation of objects by introducing the underwater coefficient;

- creation of the world water area structure of the $\mathrm{UCH}$ and identification of the richest water area;

_ introduction of a new environmental term and its structuring.

\section{Methods}

The study conducted using data presented on the official Convention for the Protection of the Underwater Cultural Heritage sites and UNESCO websites using the keyword search method and the method of spatial differentiation.

The results plotted on a map. ArcGIS Online map and FAO Major Fishing Areas layer by Living Atlas used as a cartographic basis.

The reliability of the proposed research results determined by the use of international data and practice.

\section{Results and Discussion}

The results of creating the basis of the eventual underwater cultural heritage are presented in table 1 .

Table 1 UNESCO objects as eventual Underwater cultural heritage.

\begin{tabular}{|c|c|c|c|c|c|}
\hline $\begin{array}{l}\text { Types of } \\
\text { UCH }\end{array}$ & $\begin{array}{c}\begin{array}{c}\text { Numb } \\
\text { er } \\
\text { of }\end{array} \\
\text { examples } \\
\text { by } \\
\text { ICOMOS }\end{array}$ & $\begin{array}{c}\text { Num } \\
\text { ber } \\
\text { of } \\
\text { keywords }\end{array}$ & $\begin{array}{c}\begin{array}{c}\text { Numb } \\
\text { er } \\
\text { of } \\
\text { founded } \\
\text { and } \\
\text { studied }\end{array} \\
\end{array}$ & $\begin{array}{c}\begin{array}{c}\text { Numb } \\
\text { er }\end{array} \\
\text { of objects } \\
\text { without } \\
\text { water } \\
\text { area }\end{array}$ & $\begin{array}{c}\text { Total } \\
\text { number } \\
\text { of } \\
\text { identified } \\
\text { objects }\end{array}$ \\
\hline Total & 55 & 30 & 277 & 57 & 220 \\
\hline & & & $100 \%$ & $20,6 \%$ & $79,4 \%$ \\
\hline $\begin{array}{l}\text { Number of } \\
\text { objects } \\
\text { of eventual } \\
\text { UCH }\end{array}$ & \multicolumn{5}{|c|}{275} \\
\hline
\end{tabular}


Data analysis (table 1) shows that $79.4 \%$ have the potential to be considered an underwater heritage or contain it, which is quite large for objects of exclusively natural and cultural heritage, and also proves the correlation of the two types of heritage. In view of the fact that not all the objects of the created sample have the equally potential to receive the status of $\mathrm{UCH}$, the authors introduced a submersibility coefficient based on 15 attributes.

The results of the study of the characteristics of UNESCO World Heritage sites for the value of the potential to recieve the status of underwater heritage are presented in table 2 .

Based on the coefficient, a scale was created and objects were distributed into 4 categories from a low degree of underwater to pronounced with a coefficient of 1 and 55 objects cited by UNESCO as an example as a standard of underwater heritage.

Table 2 Coefficient and scale of submersibility.

\begin{tabular}{|c|c|c|c|c|c|}
\hline $\begin{array}{l}\text { Calculation } \\
\text { formula }\end{array}$ & Index & \multicolumn{4}{|c|}{ Index value } \\
\hline \multirow{3}{*}{$W_{d}=U_{w}=\frac{N_{u}}{N_{m}}$} & $W_{d} / U_{w}$ & \multicolumn{4}{|c|}{$\begin{array}{l}\text { (water area diversity/UnderWater) - water area } \\
\text { diversity coefficient / submersibility coefficient }\end{array}$} \\
\hline & $N_{u}$ & \multicolumn{4}{|c|}{$\begin{array}{l}\text { (unique number) - number of unique quantity } \\
\text { of presence of aquatic and underwater attributes }\end{array}$} \\
\hline & $N_{m}$ & \multicolumn{4}{|c|}{$\begin{array}{l}\text { (maximum number) - number of maximum quantity } \\
\text { of presence of aquatic and underwater attributes }\end{array}$} \\
\hline & & \multicolumn{3}{|c|}{ Submersibility scale } & \\
\hline \multicolumn{2}{|c|}{ Coefficient } & 0,06 & $0,3-0,5$ & $0,5-0,7$ & $0,7-1$ \\
\hline \multicolumn{2}{|c|}{ Number of objects } & 55 & 120 & 45 & 55 \\
\hline \multirow{2}{*}{\multicolumn{2}{|c|}{ Submersibility degree }} & low & medium & high & pronounced \\
\hline & & $25 \%$ & $54,5 \%$ & $20,5 \%$ & \\
\hline
\end{tabular}

Data analysis (table 2) shows that the scale is practical and serves as a kind of guide to the sequence of research of UNESCO sites for the presence of underwater objects. Therefore, the category with a high degree included 45 objects that should be investigated earlier than the others, because they have the greatest potential to become an Underwater Cultural Heritage.

The creation of the water area structure was carried out in stages from small-scale water areas to large-scale ones. The first step was the structuring of the water areas of the oceans, which showed that the largest share of objects (67\%) is localized in the Atlantic Ocean. The next step involved zoning within the conditional boundaries of fishing areas established by the Food and Agriculture Organization of the United Nations. The most filled underwater objects were 37, 27 and 31 water areas, Fig. 1. Also on the map, there are objects of all 4 categories of eventual underwater heritage. 


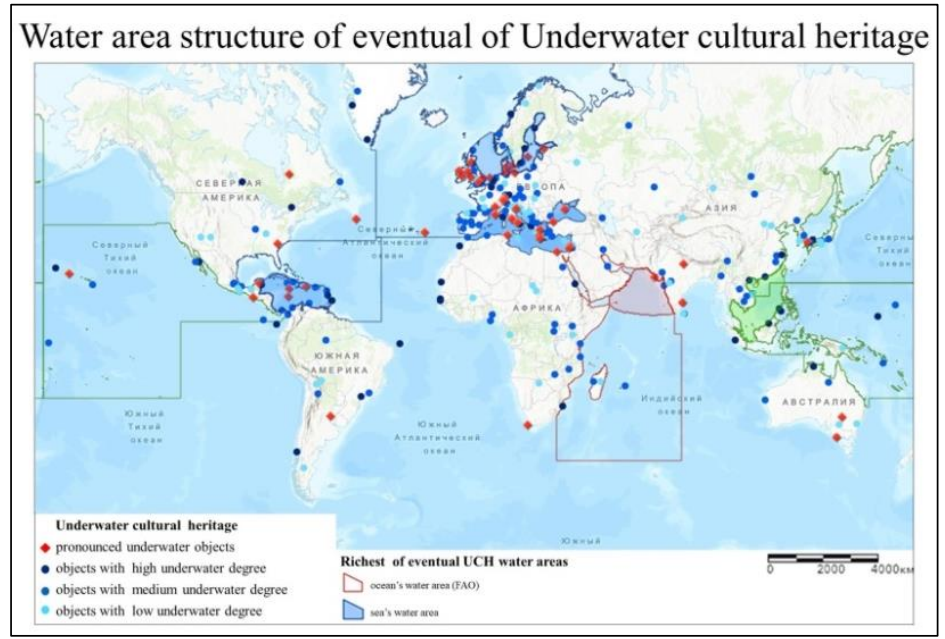

Fig. 1. UNESCO objects as eventual Underwater cultural heritage.

At the final stage of the research, zoning was performed within the boundaries of the seas. Of the 35 seas fixed during the work, the richest became water areas of 6 , including the Baltic Sea, due to rich past as a Viking pier [10]. In total, the entire Baltic water area included 17 sampling objects. However, the Institute of Heritage in the water areas of the Baltic Sea region fix about 200 specific wrecks, and according to the calculations of the Underwater Research Center of Russian Geographical society, the depths of the sea store about 30,000 shipwrecks. Theoretically, there are more catastrophes, than to any other place in the world. This means that the relevance of ecological underwater research in this region is the highest.

Nowadays the less developed field of research at the Baltic Sea, as well as around the world, is the environmental aspect of the study [7-9, 11]. The ecology of underwater heritage can be considered non-trivial and, depending on the environment surrounding the underwater heritage site. It can be divided into 2 lines of research: the ecology of shipwrecks raised from the bottom [13-16], and the ecology of wrecks located at the place of discovery [11-12], Fig. 2. Since wrecks are at the bottom of the Baltic Sea for a long period, they assimilate with the marine landscape, creating an aquatic-anthropogenic complex [7] that can be viewed from three perspectives: the influence of marine biogeocenosis on wrecks [17-18], $\mathrm{UCH}$ - is a new habitat for biota [7-9], shipwrecks is a source of pollution [11].

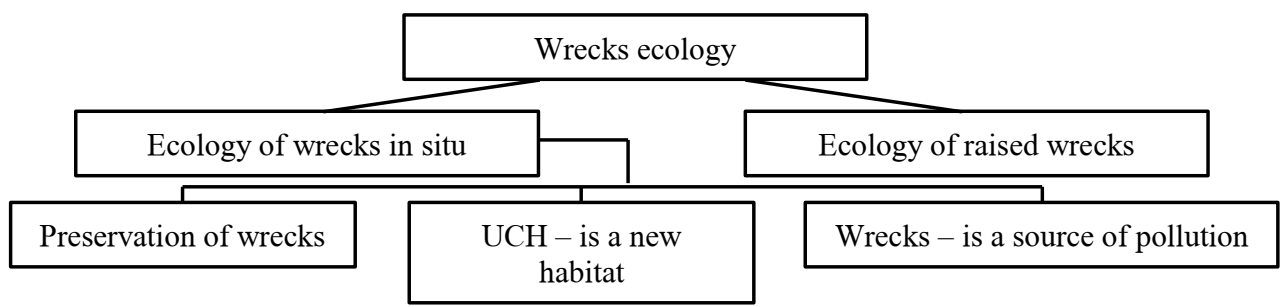

Fig. 2. UNESCO objects as eventual Underwater cultural heritage.

The most expensive trend of the ecology of UCH is raising wrecks from the bottom, conservation and museumification [19]. The best example of such world practice is the raising of the Swedish Vasa, lying on the bottom of 333 years, which took about 40 years to preserve and bring to balance, Fig. 3 [13-16]. But now it is the most visited museum in Scandinavia, which brings large revenues to the state. Working with the galleon, Sweden has gained exceptional experience and is ready to share it primarily with the countries of the 
Baltic region. Also, any nation that wants to receive answers to exquisite questions on working with the underwater heritage exempt from the depths can and should contact to the International Scientific Committee on the Underwater Cultural Heritage.

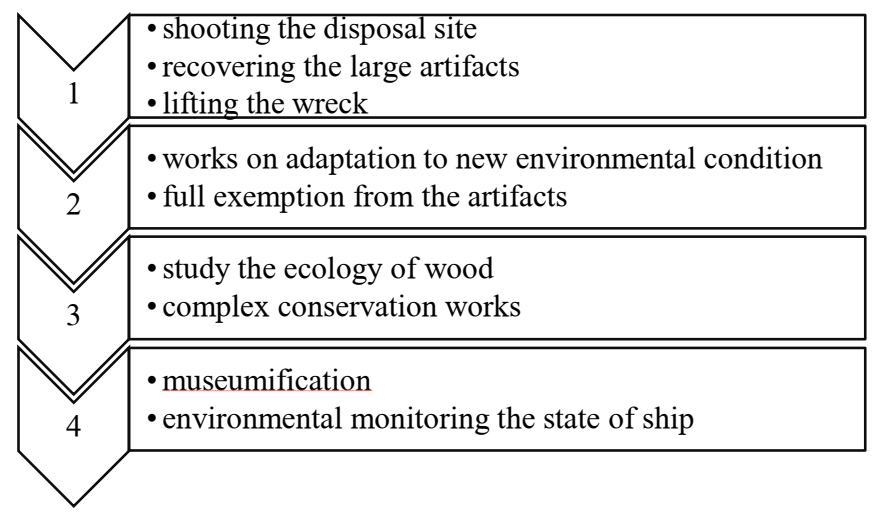

Fig. 3. Ecology of raised wrecks and UCH.

Individual specific lines of research are created by the situation in which UCH is preserved in situ, which contributes to the formation of an aquatic-anthropogenic complex. The first line of research can be distinguished the effect of biogeocenosis on a shipwreck [12]. A study of this aspect in the Baltic Sea was carried out by researchers within the framework of Wreck Protect, funded by the European Commission. According to the results of the project the Baltic region, the reasons of the increase in the shipworm population were identified and recommendations for working with wood were given.

The second direction is the study of wrecks as a new habitat for marine biota [7-9]. The Baltic Sea is not worried about the massive creation of artificial habitats for fish communities because of their small diversity [20]; for example, the Baltacar project submerges ships deliberately to increase destinations of region through the development of tourist wreckdiving.

In the near future shipwrecks as a source of pollution must be the most developed line of research, which studies and prevents the risks of fuel spills from sunken ships due to corrosion of tank walls [11]. As an example of this practice is the project that funded by the Baltic Sea Conservation Foundation for work with German tanker Franken [21].

\section{Conclusion}

The analysis of existing materials and materials created by the authors showed several definitions in underwater heritage research:

1. The lack of an internationally recognized database of underwater heritage entails difficulties and slowness in the course of scientific processes in the field of UCH. The UNESCO World Heritage List can serve as a good basis, since its objects are interdisciplinary, similar and fragmentary can become an underwater heritage, as evidenced by $20.5 \%$ of the objects of the created sample with a high degree of underwater (table 2 ).

2. The aquatorial structure of the $\mathrm{UCH}$ is best reverberated within the boundaries of the FAO fishing areas and shows that the northeast Atlantic is the richest in the content of underwater objects, where the Baltic Sea is undoubtedly the leader (Fig. 1).

3. The Baltic Sea, with high concentration of the UCH, most of all other water areas is at risk of a major ecological disaster. This non-trivial research field requires scientific 
consolidation under the new term "ecology of the underwater heritage" proposed by the authors, structured from several subareas.

Summing up the overall result, the authors would like to say that the research of the Underwater Cultural Heritage imposes on the scientific community a significant responsibility in terms of environmental safety both for the water area and for the studied object (Fig. 2). Research of the underwater heritage carried out in the Baltic Sea should represent the integration of all aspects of research with the most important, ecological, since not only the condition of the water area depends on it, but also the quality of the completeness of socio-economic and cultural development of states. Full development requires increased strengthen international cooperation between the Baltic region countries, which is wellrealized under the aegis of the Decade of Ocean Science to accelerate progress towards the 14th Sustainable Development Goals.

\section{References}

1. R. Hisakata, S. Nishida, A. Johnston, Curr. Biol., 26, 1911 (2016)

2. E. Musk, Tesla Blog (2006)

3. Conserv. Manag. Archaeol. Sites (1997)

4. S. Dromgoole, Underwater Cultural Heritage and International Law (2010)

5. S. Dromgoole, Cult. Herit. Rights (2017)

6. A. W. González, P. O’Keefe, M. Williams, Conserv. Manag. Archaeol. Sites (2009)

7. J. Flatman, Conserv. Manag. Archaeol. Sites (2009)

8. D. Blackman and D. Blackman, Oxford Dict. Natl. Biogr. (2020)

9. K. S. Meyer, S. D. Brooke, A. K. Sweetman, M. Wolf, C. M. Young, Mar. Ecol. Prog. Ser. (2017)

10. A. B. Paxton, E. A. Pickering, A. M. Adler, J. C. Taylor, C. H. Peterson, PLoS One (2017)

11. S. J. Walker, T. A. Schlacher, and M. A. Schlacher-Hoenlinger, Mar. Ecol. (2007)

12. A. Croome, Int. J. Naut. Archaeol. (1987)

13. E. Angelini, S. Grassini, S. Tusa, Corros. Conserv. Cult. Herit. Met. Artefacts (2013)

14. D. Gregory, P. Jensen, K. Strætkvern, J. Cult. Herit. (2012)

15. R. Giorgi, D. Chelazzi, P. Baglioni, Appl. Phys. A Mater. Sci. Process. (2006)

16. M. Sandström, F. Jalilehvand, I. Persson, U. Gelius, P. Frank, I. Hall-Roth, Nature (2002)

17. L. Wagner, G. Almkvist, T. K. Bader, I. Bjurhager, L. Rautkari, E. K. Gamstedt, Wood Sci. Technol. (2016)

18. E. Perez-Alvaro, J. Cult. Herit. (2016)

19. N. Gaskell, C. Forrest, N. Gaskell, C. Forrest, Law Wreck (2019)

20. G. Brice Q.C., Mar. Policy (1996)

21. H. Cho, Museum Manag. Curatorsh. (2014)

22. V. Cooper, P. Knott, J. Community Archaeol. Herit. (2016)

23. B. Hac, Biul. Inst. Morskiego (2018)

24. A. S. Baranov, O. L. Golubeva, S. Yu. Derenzhi, I. G. Filippova, Innovative approaches to the formation of an imaginative tourist space at Russian UNESCO World Heritage Sites, 11 (2018) 
25. A. S. Baranov, E. I. Bogdanov, N. O. Vereshchagina, I. G. Filippova. Monuments of the World natural and cultural heritage of Russia in the system of tourism: textbook, 310 (2020)

26. B. Asadov, A. Baranov, I. Philippova, IOP Conference Series: Earth and Environmental Science, 390 (1), 012025 (2019)

27. A. S. Baranov, A. M. Bobrova, Aquatorial approach in the study of the World Underwater Cultural Heritage, 110 (2019)

28. A. S. Baranov, I. G. Filippova, Russia in the UNESCO World Heritage System: 30 Years - Results and Prospects, 23 (2020) 